\title{
Decreased traffic volume during COVID-19 did not reduce roadkill on fenced highway network in Japan
}

\author{
Yushin Asari ${ }^{1}$ (1)
}

Received: 14 December 2020 / Revised: 4 November 2021 / Accepted: 5 November 2021 / Published online: 22 November 2021

(c) International Consortium of Landscape and Ecological Engineering 2021

\begin{abstract}
The COVID-19 pandemic has significantly reduced human activities through city lock-downs and restricted traffic flows. It had been suggested that roadkill occurrences are strongly associated with traffic volume. I evaluated the association between traffic volume and roadkill during COVID-19, from March to May 2020, using 26,130 roadkill data points recorded from the highway network in Hokkaido from 2010 to 2020, Japan. Results showed that there was a significant positive correlation between roadkill numbers and traffic volume over the past decade. However, the roadkill during COVID-19 restricted human activity did not diminish, although traffic volume decreased during this period.
\end{abstract}

Keywords COVID-19 $\cdot$ Fencing $\cdot$ Road mortality $\cdot$ Traffic volume reduction $\cdot$ WVCs

\section{Introduction}

Road construction has increased worldwide, and road length is projected to increase by $>60 \%$ from 2010 to 2050 (Dulac 2013). Roads and traffic affect ecosystems and wildlife through pollution, noise, disruption of the physical environment, and the spread of exotic species (Spellerberg 1998; Trombulak and Frissell 2000). Increasing wildlife vehicle collisions (WVCs) are related to the expansion of the road network. WVCs have a serious direct negative impact on many species. Studies have identified the factors that have the strongest effect on WVCs (Bencin et al. 2019; Williams et al. 2019). Some factors for roadkill occurrence are known; land use (Fillus et al. 2020), road characteristics and fencing (Collinson et al. 2019), ecology of species (Williams et al. 2019) and population size (Grilio et al. 2020). Traffic volume and vehicle speed are the two most important factors affecting the location and numbers of roadkill (Farmer and Brooks 2012; Lin 2016; Zhang et al. 2018; Filius et al. 2020).

In 2020, the outbreak of coronavirus COVID-19 became a global pandemic. Lockdown and significant restrictions on

Yushin Asari

asari@obihiro.ac.jp

1 Laboratory Wildlife Ecology, Obihiro University of Agriculture and Veterinary Medicine, Inada 2-11, Obihiro City, Hokkaido 080-8555, Japan human activities introduced because of this outbreak provided an opportunity to see if decreasing the traffic volume would lead to a reduction in roadkill. This study is one of the first approaches to evaluate changes in roadkill in response to the COVID-19 outbreak and the associated decrease in traffic volume.

\section{Materials and methods}

From January 2010 to May 2020, traffic volume and roadkill data were collected by the Hokkaido Regional Head Office, East Nippon Expressway Company Limited from a highway network of $719.6 \mathrm{~km}$ over Hokkaido, northern Japan (Fig. 1). Roadkills were detected by patrolling multiple times a day and reported by road users. I used total traffic volume on each month of the highway network. The highway network is entirely fenced to a height of $2.5 \mathrm{~m}$. However, mammals could invade the road, because there were some gaps between bottom edge of the fence and the ground, and between edge of the fence and structures, such as bridge. The speed limit of the highway is $70-100 \mathrm{~km} / \mathrm{h}$, and is not varied significantly among study period.

To evaluate the change in roadkill, while human activity was reduced by government controls in the Hokkaido region (28 February and 25 May 2020), I compared the traffic volume for each month with the roadkill index, which was calculated by dividing the number of roadkill for each month 


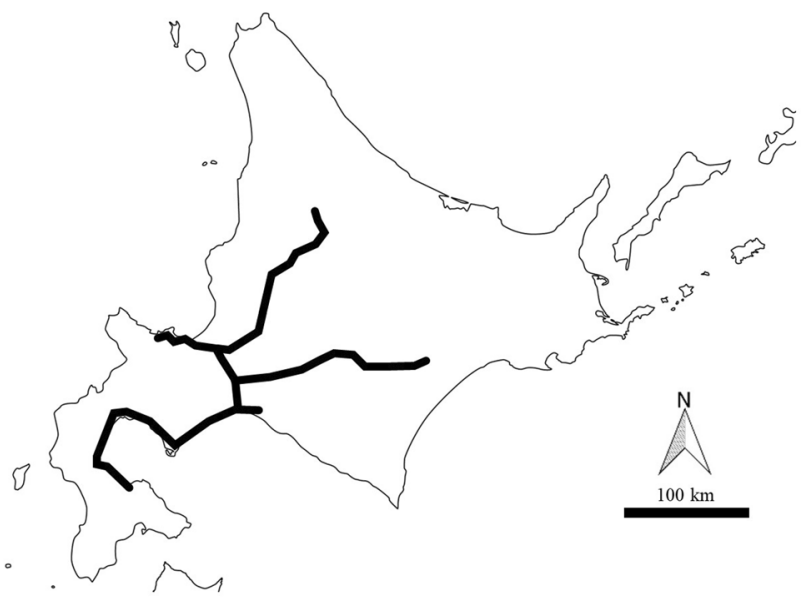

Fig. 1 Highway network managed by East Nippon Expressway in Hokkaido, Japan

by the total length of the road network. The linear regression model was performed using $\mathrm{R}$ ver. 3.4 to quantify the correlation between the amount of roadkill and traffic volume. I also used time series analysis (Auto regressive model) to confirm the trend of time series data by year and to compare between predicted value and observed value in 2020 using JMP 16. Auto regression model using roadkill index from March to May in each year as parameter is expressed as follows:

$y_{\mathrm{t}}=\varphi_{0}+\varphi_{1} y_{\mathrm{t}-1}+\varepsilon_{\mathrm{t}}$.

where $\varphi_{\mathrm{i}}$ is auto regression coefficient; and $\varepsilon_{\mathrm{t}}$ is error term of year $\mathrm{t}$.

I used significance level at 0.05 in all statistics.

\section{Results}

Roadkill numbers of raccoon dog (Nyctereutes procyonoides), red fox (Vulpes vulpes), brown bear (Ursus arctos), sika deer (Cervus nippon), birds, and unidentified mammals were recorded on the highway network. The total number of dead animals between 2010 and 2020 was 26,130 individuals (Table 1). The trend according to the value of before the year was not shown $\left(\varphi_{1}=0.32, \mathrm{SE}=0.29, t=1.13, P>0.05\right)$, when I created AR model of time series analysis based on roadkill index between 2010 and 2019. Roadkill numbers of raccoon dog varied to year between 128 and 329; however, the number of other animals did not fluctuate greatly (Fig. 2).

The mean roadkill index and traffic volume per month were 0.30 (dead animals/km/month, SD: \pm 0.17$)$ and 5,600,136.04 (vehicles/month, SD: $\pm 960,085.15$ ) vehicles, respectively. Annual average dairy traffic (AADT)
Table 1 Species of roadkill of a highway network from 2010 to 2020 in Hokkaido, Japan

\begin{tabular}{lll}
\hline Species name & Scientific name & $\begin{array}{l}\text { Number } \\
\text { of road- } \\
\text { kill }\end{array}$ \\
\hline Raccoon dog & Nyctereutes procyonoides & 8066 \\
Red fox & Vulpes vulpes & 3580 \\
Brown bear & Ursus arctos & 3 \\
Sika deer & Cervus nippon & 332 \\
Birds & & 9276 \\
Unidentified large mammals & & 7 \\
Unidentified midium mammals & & 4866 \\
Total & & 26,130 \\
\hline
\end{tabular}

ranged from 136,166 to 195,395 vehicle/day. There was a significantly positive correlation between the roadkill index and traffic volume $\left(R^{2}=0.63, F\right.$ value $=208.90, P<0.001$; Fig. 3). Roadkill index predicted based on the results of linear regression was 0.12 (March), 0.02 (April) and 0 (May) in 2020. The roadkill index from March to May 2020, when human activity was restricted, ranged from 0.22 to 0.33 . This value was within the range from 2010 to $2019(0.15-0.37$, 95\% CI 0.28-0.34). Predicted roadkill index $(0.79,95 \% \mathrm{CI}$ 0.74-0.85) from March to May in 2020 calculated using AR model of time series analysis did not also differ from observed roadkill index (0.77). However, traffic volume in 2020 decreased noticeably compared with 2010-2019 (2020: $3,314,184$ to $4,363,339 ; 2010-2019: 4,669,922$ to $6,699,206$, 95\% CI 5,478,947-5,810,639) from March to May. Examination of the change ratio which shows fluctuation of roadkill number from March to May in the roadkill index compared with the previous year showed that the value $(92 \%)$ in 2020 did not differ from other years (Table 2). However, the value of traffic volume in 2020 decreased by $65 \%$ and was lower than all the other years.

\section{Discussion}

I predicted that traffic volume would decrease during the COVID-19 pandemic, resulting in a reduction in roadkill. Over the last decade, the increase in traffic volume on the roads in Hokkaido was associated with an increase in roadkill on the highway network. Other research has shown that traffic volume is associated with WVCs (Coelho et al. 2008; D'Amico et al. 2015; Lin 2016). Helm (2020) considered that the decline of road traffic by human activity decreasing due to COVID-19 would reduce roadkill number, although there was no supporting data.

Surprisingly, I found that although traffic volume did diminish rapidly over the COVID-19 restrictions, this decrease did not reduce roadkill. Intermediate traffic 
Fig. 2 Annual roadkill numbers of each animals from March to May on the highway in Hokkaido, Japan
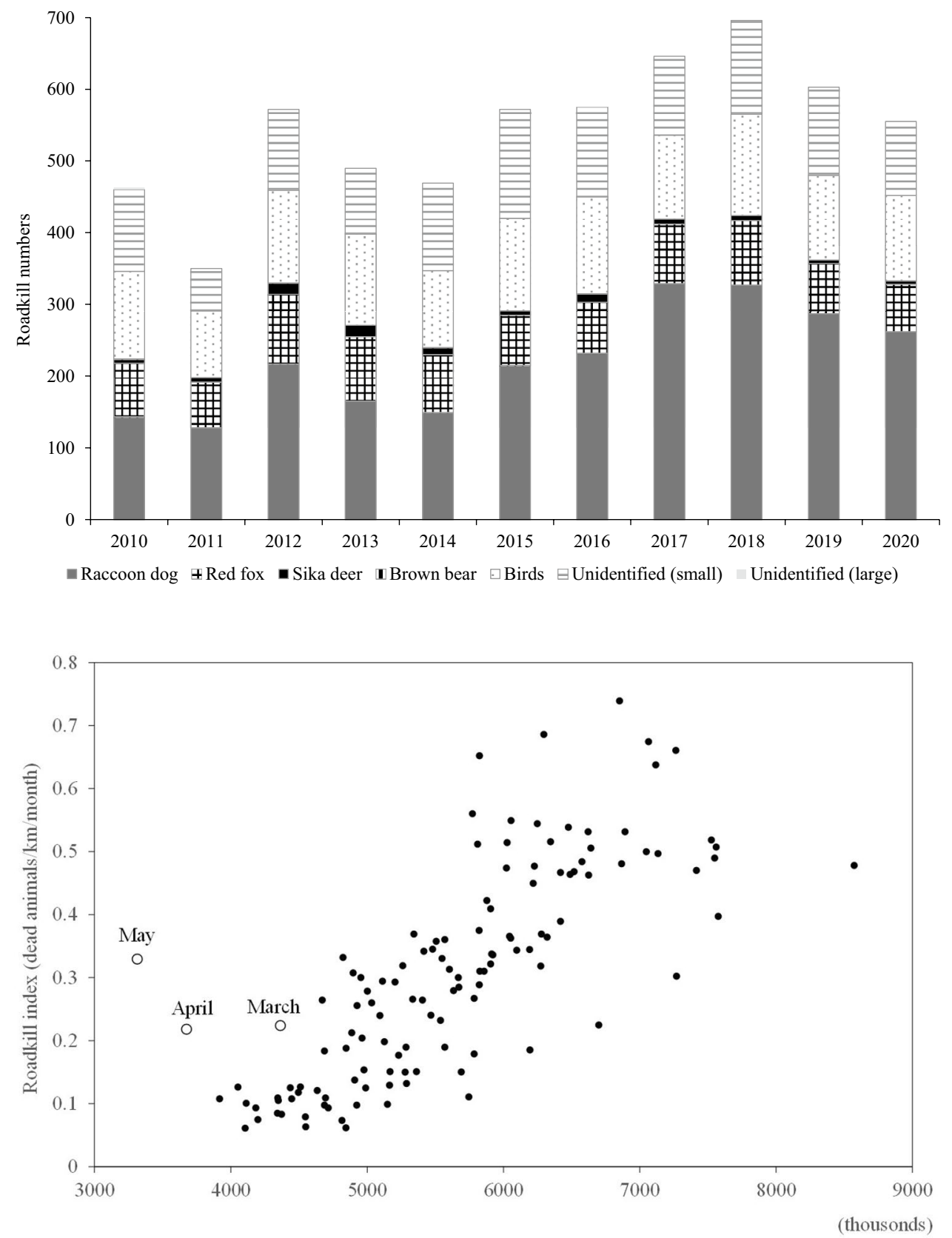

Fig. 3 Relationship between traffic volume and roadkill index. Open circles indicate the values of May, April and March in 2020. Regression formula was roadkill $=$ $-0.51+0.00000014$ traffic volume had affected for roadkill of moose Alces alces (Seiler 2005). Saeki and Macdonald (2004) also reported that roadkill of some species in Japan did not show linear regression with traffic volume, and numbers of roadkill of domestic cat and hare were high at lower and higher traffic volume. Decrease of traffic volume in this study might have the trend of increasing roadkill, although I could not clear the difference of the trend among species. Saeki and Macdonald (2004) showed that the numbers of raccoon dog roadkill differed among two scales; roadkill number increased and decreased with increasing traffic density at a nationwide scale and a local scale, respectively. Results of this study showed constant numbers of roadkill of raccoon dog. Therefore, roadkill of raccoon dog on the highway network might not affected by traffic volume. Fencing is effective for roadkill decreasing (Rytwinski et al. 2016). One reason might be because the number of animals on the roads and the associated level of roadkill has been limited by the high $(2.5 \mathrm{~m})$ fencing along the highway network in this study. Therefore, an extreme decrease in traffic volume is not necessary to reduce the amount of roadkill in the region. In addition, other factors such as landscape, vehicle speed and population size should be verified in this region. 
Table 2 Roadkill index and traffic volume in each year

\begin{tabular}{|c|c|c|c|c|c|c|c|c|}
\hline \multirow[t]{2}{*}{ Year } & \multicolumn{4}{|c|}{ Roadkill index (dead animals/km/month) } & \multicolumn{4}{|c|}{ Traffic volume (vehicles/month) } \\
\hline & March & April & May & Year-on-year & March & April & May & Year-on-year \\
\hline 2010 & 0.18 & 0.26 & 0.28 & - & $4,687,399$ & $4,669,922$ & $5,672,448$ & - \\
\hline 2011 & 0.15 & 0.18 & 0.22 & 0.76 & $5,690,330$ & $5,784,901$ & $6,699,206$ & 1.21 \\
\hline 2012 & 0.19 & 0.33 & 0.31 & 1.50 & $4,846,116$ & $4,822,753$ & $5,604,139$ & 0.84 \\
\hline 2013 & 0.15 & 0.24 & 0.31 & 0.84 & $4,975,900$ & $5,093,592$ & $5,858,333$ & 1.04 \\
\hline 2014 & 0.15 & 0.26 & 0.27 & 0.96 & $5,361,572$ & $4,926,682$ & $5,784,443$ & 1.01 \\
\hline 2015 & 0.20 & 0.31 & 0.31 & 1.22 & $4,963,083$ & $4,896,690$ & $5,826,002$ & 0.98 \\
\hline 2016 & 0.26 & 0.28 & 0.29 & 1.01 & $5,032,912$ & $5,001,836$ & $5,822,820$ & 1.01 \\
\hline 2017 & 0.26 & 0.32 & 0.34 & 1.12 & $5,406,234$ & $5,260,525$ & $6,191,045$ & 1.06 \\
\hline 2018 & 0.29 & 0.37 & 0.34 & 1.08 & $5,204,667$ & $5,342,826$ & $5,913,750$ & 0.98 \\
\hline 2019 & 0.24 & 0.28 & 0.32 & 0.84 & $5,467,744$ & $5,633,863$ & $6,273,260$ & 1.06 \\
\hline 2020 & 0.22 & 0.22 & 0.33 & 0.92 & $4,363,339$ & $3,674,720$ & $3,314,184$ & 0.65 \\
\hline
\end{tabular}

Roadkill index is shown as number of roadkill $/ \mathrm{km}$. Year-on-year shows the ratio of this year's value to the previous year
Human activity has been restricted worldwide because of the spread of COVID-19. Although this study showed that traffic volume was not associated with roadkill occurrences in this highway network, in other parts of the world understanding the effect of traffic volume restrictions may prove useful for reducing roadkill in the future.

Acknowledgements I thank Hokkaido Regional Head Office, East Nippon Expressway Company Limited, who manage the roads, for providing traffic and roadkill data. We would like to thank Editage (www.editage.com) for English language editing.

\section{References}

Bencin HL, Prange S, Rose C, Popescu VD (2019) Roadkill and space use data predict vehicle-strike hotspots and mortality rates in a recovering bobcat (Lynx rufus) population. Sci Rep-UK 9:15391. https://doi.org/10.1038/s41598-019-50931-5

Coelho IP, Kindel A, Coelho AVP (2008) Roadkills of vertebrate species on two highways through the Atlantic Forest Biosphere Reserve, southern Brazil. Eur J Wildlife Res 54:689. https://doi. org/10.1007/s10344-008-0197-4

Collinson W, Parker DM, Bernard RTF, Reilly BK, Davies-Mostert HT (2019) Factors influencing the spatial patterns of vertebrate roadkill in South Africa: the greater mapungubwe transfrontier conservation area as a case study. Afr J Ecol 57:552-564

D’Amico M, Román J, de los Reyes L, Revilla E (2015) Vertebrate road-kill patterns in Mediterranean habitats: Who, when and where. Biol Conserv 191:234-242

Dulac J (2013) Global land transport infrastructure requirements. Estimating road and railway infrastructure capacity and costs to
2050. International Energy Agency, Paris, France. https://www. iea.org/publications/freepublications/publication/TransportInfras tructureInsights_FINAL_WEB.pdf. Accessed 20 January 2019.

Farmer RG, Brooks RJ (2012) Integrated risk factors for vertebrate roadkill in southern Ontario. J Wildlife Manage 76:1215-1224

Filius J, van der Hoek Y, Jarrin-V P, van Hooft P (2020) Wildlife roadkill patterns in a fragmented landscape of the Western Amazon. Ecol Evol 10:6623-6635

Helm D (2020) The environmental impacts of the coronavirus. Environ Resour Econ 76:21-38

Lin S-C (2016) Landscape and traffic factors affecting animal road mortality. J Environ Eng Landsc 24:10-20

Rytwinski T, Soanes K, Jaeger JAG, Fahrig L, Findlay CS, Houlahan J, van der Ree R, van der Grift E (2016) How effective is road mitigation at reducing road-kill? a meta-analysis. PLoS ONE 11:e0166941. https://doi.org/10.1371/journal.pone.0166941

Saeki M, Macdonald DW (2004) The effects of traffic on the raccoon dog (Nyctereutes procyonoides viverrinus) and other mammals in Japan. Biol Conserv 118:559-571

Seiler A (2005) Predicting locations of moose-vehicle collisions in Sweden. J Appl Ecol 42:371-382

Spellerberg I (1998) Ecological effects of roads and traffic: a literature review. Global Ecol Biogeogr 7:317-333

Trombulak SC, Frissell C (2000) Review of ecological effects of roads on terrestrial and aquatic communities. Conserv Biol 14:18-30

Williams ST, Collinson W, Patterson-Abrolat C, Marneweck DG, Swanepoel LH (2019) Using road patrol data to identify factors associated with carnivore roadkill counts. Peer J 7:e6650. https:// doi.org/10.7717/peerj.6650

Zhang W, Shu G, Li Y, Xiong S, Liang C, Li C (2018) Daytime driving decreases amphibian roadkill. Peer J 6:e5385. https://doi.org/10. 7717/peerj.5385 